\title{
Cloning and expression of a novel chicken sulfotransferase cDNA regulated by $\mathrm{GH}$
}

\author{
H Cao $^{1}$, S K Agarwal ${ }^{1}$ and J Burnside ${ }^{2}$ \\ ${ }^{1}$ Department of Biology, University of Delaware, Newark, Delaware 19717, USA \\ ${ }^{2}$ Department of Animal and Food Science, University of Delaware, Newark, Delaware 19717, USA \\ (Requests for offprints should be addressed to J Burnside) \\ (S K Agarwal is now at NIH/NIDDK, Metabolic Disease Branch, Building 10, Room 9C-101, Bethesda, Maryland, USA)
}

\begin{abstract}
We have used mRNA differential display to compare gene expression in normal and GH receptor-deficient dwarf chickens, and report here the characterization of one differentially expressed gene, which shows significant sequence identity to the sulfotransferase gene family. Partial cDNA clones were isolated from a chicken liver cDNA library and an additional sequence was obtained using $5^{\prime}$ rapid amplification of cDNA ends. A complete cDNA probe hybridizes to three transcripts $(2 \cdot 4,2 \cdot 0$ and $1.45 \mathrm{~kb}$ ) on Northern blots of chicken liver RNA, which differ in the length of the $3^{\prime}$ untranslated region. All three transcripts are expressed at higher levels in normal vs dwarf chickens, as expected for a GH-regulated gene. The expression of this sulfotransferase mRNA was also detected in skeletal muscle, but not other tissues. The administration of $\mathrm{GH}$ to chickens increased the hepatic
\end{abstract}

expression within $1 \mathrm{~h}$, suggesting this sulfotransferase could be directly regulated by GH. Sulfotransferase activity, using estradiol or corticosterone as substrate, is detected in cells transfected with an expression vector containing the full-length cDNA. The sequence of this sulfotransferase does not show significant similarity with any subfamily of the sulfotransferases and its endogenous substrate is presently unknown. However, we speculate that $\mathrm{GH}$ activation of sulfotransferase activity could play a role in reducing concentrations of growth-antagonistic steroid hormones in GH target tissues. These results demonstrate the usefulness of differential display in this model system to identify genes that play a role in mediating $\mathrm{GH}$ action.

Journal of Endocrinology (1999) 160, 491-500

\section{Introduction}

Growth hormone (GH) exerts a wide range of cell- and tissue-specific responses, including regulation of lipid, nitrogen and carbohydrate metabolism, as well as induction of cell growth and differentiation. These effects are mediated by the binding of $\mathrm{GH}$ to its cell surface receptor (GHR), activation of downstream cellular signal transduction events and altered expression of specific genes in target cells. Despite the multitude of effects of $\mathrm{GH}$ on growth and metabolism, relatively few GH-regulated genes have been well characterized or their role in $\mathrm{GH}$ action determined. Many studies looking at the action of $\mathrm{GH}$ have used hypophysectomized animals which are deficient in all pituitary hormones, not just GH (Berry et al. 1986, Yoon et al. 1987). We have used the sex-linked dwarf chicken as a model to study the actions of GH. These animals are pituitary intact, but the absence of a functional GHR in the dwarf results in a complete absence of $\mathrm{GH}$ action. We have previously reported on the molecular mutation in the GHR gene in the Georgia line of dwarf chickens (Huang et al. 1993). By using the
mRNA differential display technique (Liang \& Pardee 1992, Liang et al. 1992, 1993) to compare gene expression in livers of normal and dwarf chickens, we have noted differences in the steady-state mRNA levels of a large number of genes (Agarwal et al. 1995). Using this approach, we isolated and characterized a cysteine protease inhibitor whose pattern of expression suggests it is a GH-regulated gene (Agarwal et al. 1995, Radecki et al. 1997). Characterization of a second differentially expressed cDNA is described here.

A complete cDNA was obtained through cDNA library screening and $5^{\prime}$ rapid amplification of cDNA ends $\left(5^{\prime}\right.$ RACE). A comparison of the 312 deduced amino acid sequence with the GenBank database indicates the cDNA is a member of the sulfotransferase gene family. Sulfonation is important in the metabolism of many endogenous and exogenous compounds, such as steroid hormones and xenobiotics (Mulder \& Jakoby 1990). There have been several reports on $\mathrm{GH}$ regulation of estrogen and thyroid hormone sulfotransferase activity, although the physiological role of these enzymes in regards to $\mathrm{GH}$ action is unclear (Yamazoe et al. 1987, Gong et al. 1992). We speculate that 
the growth-promoting activities of $\mathrm{GH}$ are mediated in part through tissue-specific regulation of the activity of hormones such as estradiol or corticosterone, which can retard growth (Freundenberger \& Hashimoto 1937, Murphy \& Friesen 1988, Luo \& Murphy 1989, King \& Carter-Su 1995).

\section{Materials and Methods}

\section{Experimental animals}

The normal and dwarf broiler chickens used in this study are maintained at the University of Georgia and are of the same genetic background (Marks 1982). Fertile eggs were shipped by air to the University of Delaware for hatching. Animals were handled in accordance with the principles and procedures outlined by the University's Animal Care and Use Committee. In experiments on determining in vivo effects of $\mathrm{GH}, 8$-week-old chickens were injected i.m. with saline or chicken $\mathrm{GH}(\mathrm{cGH})(100 \mu \mathrm{g} / \mathrm{kg}$ body weight) and killed 1, 2, 4, 8, 16 or $24 \mathrm{~h}$ later (four birds per time point). (Recombinant cGH was kindly provided by Dr Larry Cogburn, University of Delaware.)

\section{Materials}

RNAmap mRNA Differential Display system was purchased from GenHunter Corporation (Brookline, MA, USA). Cell culture reagents and the 5' RACE system were purchased from Life Technology, Inc. (Gaithersburg, MD, USA). RACE products were cloned using the Original TA cloning kit obtained from Invitrogen (San Diego, CA, USA). Radiolabeled nucleotides were purchased from New England Nuclear (Boston, MA, USA). RNeasy RNA miniprep kit was purchased from Qiagen (Chatsworth, CA, USA). Oligonucleotides were synthesized by Biosynthesis, Inc. (Lewisville, TX, USA). $\lambda$ ZAP chicken liver cDNA library and pSG5 expression vector were purchased from Stratagene (La Jolla, CA, USA). Poly(A)Tract mRNA isolation system, Wizard PCR Preps, Wizard Minipreps DNA purification systems and enzymes were purchased from Promega (Madison, WI, USA). RediPrime random primer labeling kits and sequencing reagents were obtained from Amersham (Arlington Heights, IL, USA). BCA protein assay kit was purchased from Pierce (Rockford, IL, USA). 3'Phosphoadenosine $5^{\prime}$-phosphosulfate (PAPS) was from Sigma Chemical Co. (St Louis, MO, USA).

\section{$m R N A$ differential display}

Poly(A) RNA $(0 \cdot 5 \mu \mathrm{g})$, prepared from 5-week-old normal and dwarf chickens, was reverse transcribed with each of the four anchored oligo dT primers, ${ }^{5^{\prime}} \mathrm{GMT}_{12}{ }^{3^{\prime}}$, ${ }^{5^{\prime}} \mathrm{AMT}_{12}{ }^{3^{\prime}},{ }^{5^{\prime}} \mathrm{TMT}_{12}{ }^{3^{\prime}}$ and ${ }^{5^{\prime}} \mathrm{CMT}_{12}{ }^{3^{\prime}}$ where ' $\mathrm{M}$ ' is a degenerate mixture of $\mathrm{dA}, \mathrm{dC}$ and $\mathrm{dG}$. Amplification and isolation of cDNA fragments were performed in accordance with the manufacturer's instructions. Selected PCR products were excised from the dried sequencing gel, amplified and random primer labeled for use as probes.

\section{Screening of $c D N A$ library}

A commercially prepared chicken liver cDNA library (Stratagene) in $\lambda$ ZAP was screened by hybridization of duplicate filter lifts (approximately $600000 \mathrm{pfu}$ ) with a radiolabeled cDNA obtained from amplification of the differential display fragment. Plasmids were excised from positive purified plaques using the in vivo excision protocol according to the manufacturer's instructions and then subjected to sequence analysis with primers flanking the polylinker and primer walking. Sequence was analyzed on MacVector 4.5.3 (Kodak, Rochester, NY, USA) and compared with the NCBI database using the Basic Local Alignment Search Tool (BLAST) (Altschul et al. 1990, Gish \& States 1993). Alignment with related sequences was performed using the Clustal method of the DNAStar MegAlign program.

\section{Northern and Southern blot analyses}

Total RNA was isolated from tissues of normal and dwarf chickens by the method of Chirgwin et al. (1979) or with an RNeasy kit. Northern blot analysis was performed as described previously (Huang et al. 1993). Chicken glyceraldehyde-3-phosphate dehydrogenase (GAPDH) or 18S RNA cDNA probes were used to monitor quality and quantity of RNA (Dugaiczk et al. 1983). The abundance of the chicken sulfotransferase cDNA was determined by laser densitometry and fold induction determined after normalization to the levels of GAPDH mRNA.

Chromosomal chicken liver DNA was prepared using standard procedures (Sambrook et al. 1989), then digested with restriction enzymes BamHI, NcoI, NdeI and TaqI and subjected to Southern blot analysis as described previously (Burnside et al. 1991).

\section{$5^{\prime} R A C E$}

Two nested primers were designed based on the known sequences obtained from partial cDNA clones. They are GSP1: 5' GAGGCAATGTTTTTCACTCCCAGGG 3'; GSP2: 5' GCAGCATATTTGTTCCATTCAGAAAGG $3^{\prime}$. These are complementary to nt 729-753 and nt 652-678 respectively of the full-length sulfotransferase cDNA. Using mRNA prepared from the liver of a 5-week-old chicken, first-strand cDNA synthesis was performed using GSP1. Purification and TdT tailing of the cDNA were performed according to manufacturer's protocols. PCR amplification of dC-tailed cDNA was carried out using GSP2 and a poly $(G)$ primer, following an initial 
A

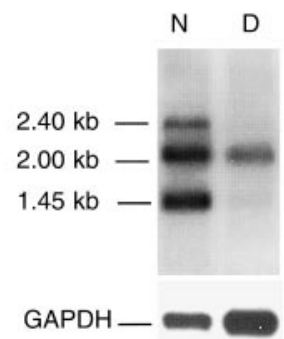

B

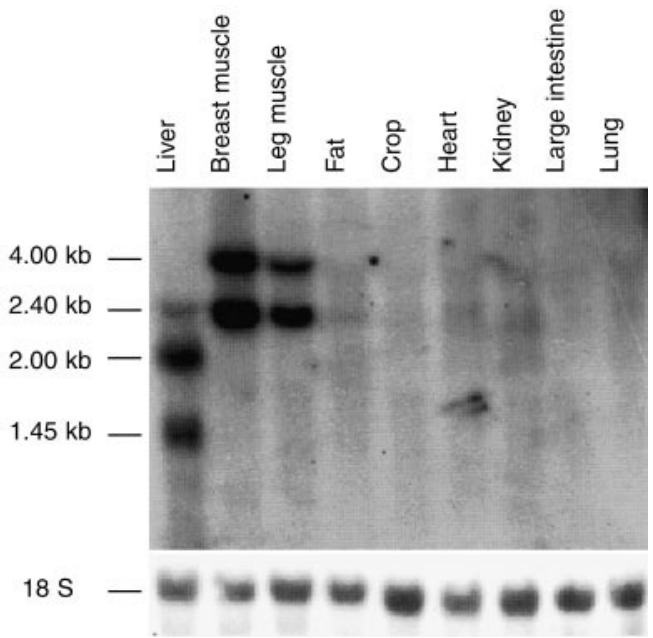

Figure 1 Northern blot analysis of chicken sulfotransferase. (A) Blots of poly(A) mRNA $(2 \mu \mathrm{g})$ from livers of 5-week-old normal $(\mathrm{N})$ and dwarf (D) chickens. (B) Blots of total RNA $(25 \mu \mathrm{g})$ from different tissues isolated from a 5-week-old normal male chicken. Blots were hybridized to a probe for either GAPDH (A) or 18S RNA (B) to show intact RNA in all lanes.

incubation at $94^{\circ} \mathrm{C}$ for $5 \mathrm{~min}$. PCR conditions were $94{ }^{\circ} \mathrm{C}$ for $30 \mathrm{~s}, 48^{\circ} \mathrm{C}$ for $1 \mathrm{~min} 30 \mathrm{~s}$ and $72{ }^{\circ} \mathrm{C}$ for $2 \mathrm{~min}$ for 40 cycles, followed by extension at $72{ }^{\circ} \mathrm{C}$ for $7 \mathrm{~min}$. A product of $725 \mathrm{bp}$ was obtained, cloned into TA vector and sequenced.

\section{Transfection and transient expression of chicken sulfotransferase}

A full-length cDNA (nt 1-1183) was constructed using a BamHI site (nt 636) present in the $5^{\prime}$ end of the partial cDNA clone obtained from library screening, and in the $3^{\prime}$ end of the $5^{\prime}$ RACE product. The fragments were ligated into pSG5 and orientation determined by restriction mapping. The integrity of the BamHI ligation site was verified by sequencing.

Cells (293, ATCC CRL 1573) were plated in $150 \mathrm{~cm}^{2}$ culture flasks in Dulbecco's modified Eagle's medium/F12 containing penicillin $(100 \mathrm{U} / \mathrm{ml})$, streptomycin $(50 \mu \mathrm{g} / \mathrm{ml})$ and $10 \%$ calf serum. Cells were transfected with chicken sulfotransferase expression plasmid (30 $\mu \mathrm{g})$ using calcium phosphate.

Sulfotransferase activity was measured $36-48 \mathrm{~h}$ posttransfection using a modification of a previously reported method (Tomizuka et al. 1994). Cytosolic protein $(250 \mu \mathrm{g})$ was incubated with $100 \mu \mathrm{M}$ PAPS and $0 \cdot 4 \mu \mathrm{M}$ $\left[{ }^{3} \mathrm{H}\right]$ estradiol or $\left[{ }^{3} \mathrm{H}\right]$ corticosterone in a total volume of $200 \mu \mathrm{l}$ assay buffer containing $190 \mathrm{mM}$ Tris- $\mathrm{HCl}$ (pH 7.8), $10 \mathrm{mM} \mathrm{MgOAc}$ and 0.25 mM dithiothreitol. Blanks were prepared without the addition of PAPS or cytosol and all assays were performed in duplicate. After $30 \mathrm{~min}$ incubation at $37^{\circ} \mathrm{C}$, reactions were stopped by the addition of $400 \mu \mathrm{l}$ distilled water. The reaction was immediately extracted with $2 \mathrm{ml}$ dichloromethane, and the radioactivity of sulfoconjugated steroid remaining in the aqueous phase was determined by liquid scintillation counting. The assay was linear with respect to time and protein concentration.

\section{Results}

Analysis of chicken sulfotransferase expression in normal and dwarf chickens

Differential display of normal and dwarf chicken liver revealed a large number of differentially expressed RNAs, as reported previously (Agarwal et al. 1995). A cDNA fragment, which was displayed at higher levels in normals compared with dwarfs, was recovered from the differential display gel, reamplified and used as a probe on Northern blots of liver RNA from normal and dwarf chickens. The cDNA hybridizes to three transcripts of $1.45,2.0$ and $2 \cdot 4 \mathrm{~kb}$, which are all expressed at higher levels (approximately $2 \cdot 5$-fold) in normal chickens compared with dwarf chickens (Fig. 1A).

To examine tissue-specific expression, Northern blots of total RNA from a number of tissues were hybridized to the cDNA probe (Fig. 1B). Of the tissues examined, only liver and muscle had detectable levels of hybridizing species; however, the pattern of expression is different in these two tissues. In liver, the 1.45 and $2.0 \mathrm{~kb}$ transcripts were expressed at high levels and the $2.4 \mathrm{~kb}$ transcript was less abundant. In contrast, the two smaller transcripts were not present in muscle, but instead there was high abundance of the $2 \cdot 4 \mathrm{~kb}$ and of a larger transcript $(4 \cdot 0 \mathrm{~kb})$, in both breast and leg (iliotibialas) muscle, but not in cardiac muscle. The pattern and relative abundance were 


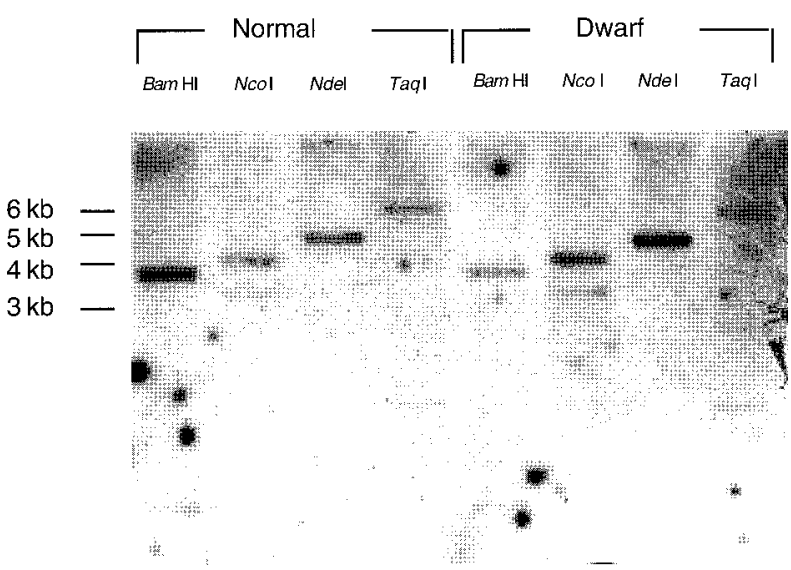

Figure 2 Southern blot analysis of genomic DNA from normal and dwarf chickens. DNA $(20 \mu \mathrm{g})$ was digested with the indicated enzymes, electrophoresed on a $0 \cdot 8 \%$ agarose gel and transferred to a nylon membrane. The blot was hybridized to a random primer labeled full-length chicken sulfotransferase cDNA probe.

similar in both males and females, indicating there is no sexual dimorphism in the expression of this cDNA (data not shown).

In order to further elucidate the nature of the multiple hybridizing species present on Northern blots and the differences in expression between the normal and dwarf strains, Southern blot analysis was performed under the same conditions of stringency as the Northern blot analysis. The simple pattern displayed on Southern blot analysis (Fig. 2) is consistent with the cDNA only hybridizing to a single gene, suggesting that the multiple transcripts on Northern blots are derived from the same gene, rather than due to hybridization with different members of the sulfotransferase family. In addition, the restriction patterns are identical with normal and dwarf DNA, indicating the differences in the levels of gene expression are not likely to be due to gross aberrations in the chicken sulfotransferase gene in the dwarf chicken.

Because dwarf chickens have no functional GHR, and consequently no mechanism for regulating GH-dependent gene expression, the higher levels of mRNA found in normal chickens indicate it is a candidate for a $\mathrm{GH}$ regulated gene. To determine if the effects of $\mathrm{GH}$ on gene expression could be reproduced in intact animals, mRNA levels were determined in livers of chickens treated with GH. Eight-week-old chickens were used since they have very low endogenous $\mathrm{GH}$ levels, but relatively high GHR levels (Burnside \& Cogburn 1992). As shown in Fig. 3, there was a significant increase in mRNA levels $1 \mathrm{~h}$ after injection and a peak at $4 \mathrm{~h}(P \leq 0 \cdot 05)$. mRNA levels declined by 8 and $16 \mathrm{~h}$, but increased again at $24 \mathrm{~h}$. In comparison, chicken GHR mRNA levels also increased $1 \mathrm{~h}$ after $\mathrm{GH}$ administration, peaked at $4 \mathrm{~h}$, then declined and remained at the preinjection level for the duration of the study. While these results do not definitively show that
$\mathrm{GH}$ directly induces the expression of this gene, the rapidity of the response to $\mathrm{GH}$ is consistent with a direct effect.

\section{cDNA sequence analysis}

The cDNA fragment obtained from the differential display gel was used as a probe to screen a chicken liver cDNA library. Several positive clones were isolated, sequenced and found to overlap in the $5^{\prime}$ end. The $5^{\prime}$ RACE procedure was used to obtain the $5^{\prime}$ end of the cDNA sequence. A single predominant PCR product of $725 \mathrm{bp}$ was obtained, cloned and sequenced; this fragment contains an $83 \mathrm{bp}$ overlap with the largest library clone. Computer analysis of the combined nucleotide sequence revealed a $936 \mathrm{bp}$ open reading frame flanked by a $70 \mathrm{bp}$ $5^{\prime}$ untranslated region (UTR) (Fig. 4), using the ATG at nt 71 as the initiator methionine. There is a second in-frame ATG at nt 134 and no stop codons in between. Thus, we cannot unambiguously assign the initiator methionine, as both show reasonable consensus for translation initiation according to Kozak's rules (Kozak 1989). Hydropathy plot analysis of the deduced amino acid sequence did not indicate the presence of a signal peptide or any transmembrane domains, suggesting that this cDNA codes for a cytosolic protein. A comparison of the predicted amino acid sequence with GenBank database revealed significant sequence similarity to the sulfotransferase gene family (described below).

The isolation of two cDNA clones from a chicken liver cDNA library which differ in the 3' UTR, in conjunction with the presence of multiple transcripts on Northern blots, suggests alternative splicing or alternative polyadenylation is used to generate the different transcripts. In order to clarify this, domain-specific cDNA probes were generated and hybridized to identical blots of mRNA from liver. As shown in Fig. 5, all transcripts hybridized to a probe containing the $5^{\prime}$ UTR or the coding region; however, hybridization with probes corresponding to different portions of the $3^{\prime}$ UTR indicated that the three transcripts differ in the $3^{\prime}$ UTR. This is consistent with the finding that one of the positive library clones terminated at nt 790 and contained a poly(A) tail. This cleavage site is likely used to generate the $2 \cdot 0 \mathrm{~kb}$ transcript. There does not appear to be a canonical polyadenylation signal in association with either $3^{\prime}$ terminus. The location of the cleavage site used to generate the $1.45 \mathrm{~kb}$ transcript was not determined.

\section{Comparison of deduced amino acid sequence with sulfotransferase cDNAs}

Figure 6 shows a comparison of the predicted amino acid sequence of chicken sulfotransferase with other sulfotransferases which show the highest level of sequence similarity, based on BLAST analysis. At least 19 different 


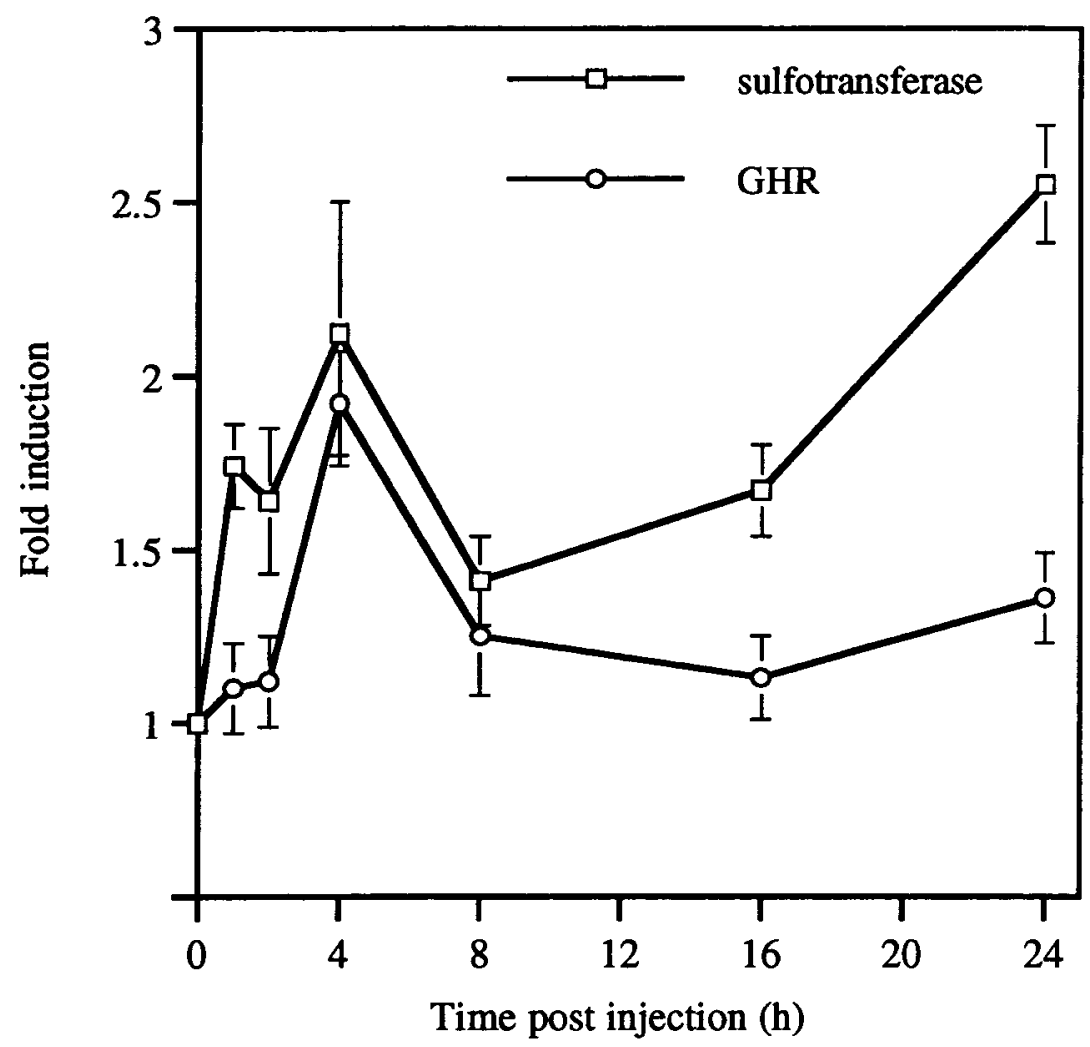

Figure 3 Effects of in vivo administration of $\mathrm{cGH}$ on hepatic chicken sulfotransferase mRNA levels. Normal male chickens ( 8 weeks old, four per time point) were treated with a single i.m. injection of either saline (control) or $\mathrm{cGH}(100 \mu \mathrm{g} / \mathrm{kg}$ body weight), and killed at the times indicated. RNA was prepared from livers and subjected to Northern blot analysis, using either a radiolabeled chicken sulfotransferase or GHR cDNA probe. Blots were hybridized to a GAPDH probe for normalization. Autoradiographs were scanned using a laser densitometer; relative changes in all chicken sulfotransferase transcripts were superimposable. Data points represent means of four animals for each time point \pm S.E.M.

sulfotransferases have been isolated from various classes and species and this large gene family has been further divided into subfamilies based on sequence similarity and substrate specificity (Yamazoe et al. 1994). Previous studies comparing the deduced amino acid sequence of sulfotransferases of plant, bacterial and animal origin have revealed significant homology in several well-conserved domains (Kong et al. 1992). The recent determination of the crystal structure of estrogen sulfotransferase allowed further localization of residues involved in substrate binding (Kakuta et al. 1998). The highly conserved sequences involved in binding the $5^{\prime}$ and $3^{\prime}$ phosphates of PAPS (amino acids 63-69 and 267-274 respectively) are present in chicken sulfotransferase. In addition, arginine 148 and serine 156, which are also involved in binding the $3^{\prime}$ phosphate, are conserved. Histidine 126 is thought to be involved in catalysis and is found in all sulfotransferases. In the crystal structure, the steroid-binding pocket includes residues in the vicinity of phenylalanine 160 , which is conserved in a number of sulfotransferases with different substrate specificities (Kakuta et al. 1998). Other lessconserved residues in this region and the region around amino acid 262 likely confer specificity. However, the sequence of chicken sulfotransferase in these regions does not show sufficient similarity with other cloned sulfotransferases to indicate the identity of the endogenous substrate.

\section{Expression of cloned chicken sulfotransferase in 293 cells}

In order to determine if chicken sulfotransferase encodes a protein possessing sulfotransferase activity, the full-length cDNA was cloned into a eukaryotic expression vector and transfected and transiently expressed in 293 cells. Cytosolic protein from transfected and untransfected cells was assayed for sulfotransferase activity, using $\left[{ }^{3} \mathrm{H}\right]$ estradiol and $\left[{ }^{3} \mathrm{H}\right]$ corticosterone as substrates. Mock-transfected 293 cells had very low endogenous sulfotransferase activity; however, cells transfected with the chicken sulfotransferase cDNA showed a 14- and 8-fold increase in sulfotransferase activity with either estradiol or corticosterone 
CAACCAGTGTCTCTCTGTCTGTGTAGCATTTCACATT GT GACA 44 GAGATTGTGTGTGTGAGAGAGAGAAGA ATG GAA AAA TCT AGG AAG AAA TTT ATT $M$ E K S R K K F I 9

98 GAT GTG ATA GAT AAG GCA ATA GTT ATT GGT AAT GCA ATG GAT CGT GAT $\begin{array}{lllllllllllllllll}D & V & I & D & K & A & I & V & I & G & N & A & M & D & R & D & 25\end{array}$ 146 GAA CTG CTT TTT TCT TAC AAG GGG GTT CTC TAC CCT GTT GCT CTT TGC

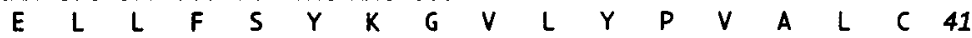

194 AGT CCT GAA GTA TTC AGA GCC ATG GAG TCC TTT GAA GCC AGA AGT GAT $\begin{array}{lllllllllllllllll}S & P & E & V & F & R & A & M & E & S & F & E & A & R & S & D & 57\end{array}$

242 GAT GTC ATT TTG GCA GGA TAT CCT AAA TCT GGT ACA AAC TGG GTA GGT $\begin{array}{lllllllllllllllll}D & V & I & L & A & G & Y & P & K & 5 & G & T & N & W & V & G & 73\end{array}$

290 CAG ATC TTA AGT GAT CTG GTG GCC ACA TTT GAA AAA GAA AGA CTT GAA $\begin{array}{lllllllllllllllll}Q & I & L & S & D & L & V & A & T & F & E & K & E & R & L & E & 89\end{array}$

338 GAA AAA AGT GTT AAT GAT GAA GAG CTA GAA GAA TTT CCG TAC CTT GAA

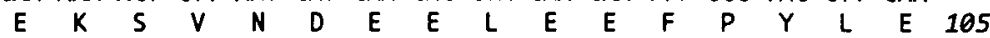

386 ATT GGA GAT ACT GAG AAA TAT GAG CGA ATG AAG AAG TTA CCT TCT CGA $\begin{array}{lllllllllllllllll}I & G & D & T & E & K & Y & E & R & M & K & K & L & P & S & R & 121\end{array}$

434 AGA GTT ATA TTA ACT CAT CTA TCT CCT GAA AAG CTC CCA AAG TCC ATC $\begin{array}{lllllllllllllllll}R & V & I & L & T & H & L & S & P & E & K & L & P & K & S & I & 137\end{array}$

482 TTC AAA AAT AAA GCC AAG ATA CTG CTG CTG ATT CGC AAT CCG AAA GAT

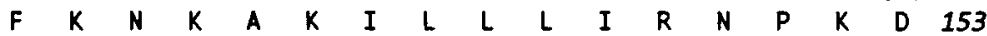
530 ATA GCT ACA TCA TTT TTC CAT TTT TCC AAT CGC TGG TCG GCT CTA CCC $\begin{array}{lllllllllllllllll}I & A & T & S & F & F & H & F & S & N & R & W & S & A & L & P & 169\end{array}$

578 TCC TAT GAG ACC TGG GAT GAT TTC TTC ATA GCT TTC ATG ACA GAG AAA $\begin{array}{lllllllllllllllll}S & Y & E & T & \text { W } & D & D & F & F & I & A & F & M & T & E & K & 185\end{array}$

626 ATG CCC TGG GGA TCC TAC TTT AAC TAC CTT TCT GAA TGG AAC AAA TAT $\begin{array}{lllllllllllllllll}M & P & W & G & S & Y & F & N & Y & L & S & E & W & N & K & Y & 201\end{array}$ 674 GCT GCT GAT GAA AAT GTT ATG ACA ATA ACA TAT GAA GAA CTA AAA GAG $\begin{array}{lllllllllllllllll}A & A & D & E & N & V & M & T & I & T & Y & E & E & L & K & E & 217\end{array}$ 722 AAT CAA ACC CTG GGA GTG AAA AAC ATT GCC TCT TTC TTT GGG ATT TCC $\begin{array}{lllllllllllllllll}N & Q & T & L & G & V & K & N & I & A & S & F & F & G & I & S & 233\end{array}$

770 CTG ACT GGG GAA GAG CTT CGG AGC GTG ATA GAG AGG AGC AGT TTC CAG $\begin{array}{lllllllllllllllll}L & T & G & E & E & L & R & S & V & I & E & R & S & S & F & Q & 249\end{array}$

818 TCC ATG AAG GAG AAC TCT CTG AAG ACC CAT GGG GCT CTG GGC AGC ATG $\begin{array}{lllllllllllllllll}S & M & K & E & N & S & L & K & T & H & G & A & L & G & S & M & 265\end{array}$

245 CTC TTT CGC AAA GGT GGT GTA AGC GAC TGG AAG AAT CTT TTC AAT GAG $\begin{array}{llllllllllllllllllllllll}L & F & R & K & G & G & V & S & D & \text { W } & K & N & L & F & N & E & 281\end{array}$

914 GAG CAG AAT GAG AAA ATG GAC AAA GTA TTT GAA GAA CGC ATA GCA AGA

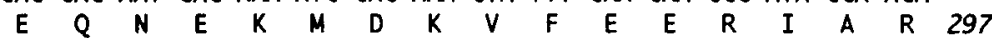
962 ACG AAA CTA GGA ACA AAG TTA AAG TAT GAA GTG TAC TGC AAA GCC TGA $\begin{array}{lllllllllllllll}T & K & L & G & T & K & L & K & Y & E & V & Y & C & K & \text { A } \\ \text { AGAATAACGAAATATGGTTTGACCAATAGCTTTCCACTGTGCTCTTCAATCTGAATGATACAC } & 3\end{array}$ 1010 AGAATAACGAAATATGGTTTGACCAATAGCTTTCCACTGTGCTCTTCAATCTGAATGATACAC 1136 ACCTTTACAGT GACAACAATGAATAGTTGGCTTTTT GTTTTAAATGTGAGATCTTATTTGGCTA 1199 CATTCATTTGCTGAATATGATGGTAAATAACCATATCAGGTAAACTT GACAGGCTTGTTACAG 1262 TAGCTGCCACCTGAAAGGAAATGGCCTTTTTTGCTTTCCAGGCAAACTCAGTCATTCTAGAAA 1325 ATTTACATAGGGTTATTTAGAATGT GGAGAATCTTTTTTTTTTTTCTTCCCAAAAATGCCTCAG 1388 ATCAGGT GAGATCTCCACAATTAAGATCGCT GT CAAAATACGGATCT GACATAGCCTTAATTA 1451 ATGACAAATATCTTCCCTGTGACTTCAGCACAAACTGGATAAAAGCTAGAGGGAGGATAATGA 1514 AAGGGAATGACAATCATCATTTTAAGGACTTTAATCTCTCCAAGT GTAGAATTTCAAGCTGAA 1577 ATTCAGATTACAGATTGGTATTAACAGCCAAGATCCAAT GAGAAGCACCATTTTTAT GTATAA 1640 TAATT CT CTTT GT GGAACACAACAAAAATCT CAAATTAATTTTCTTTCTAATATCAT GCACAT 1703 TTTCTCTTGGT CCACTGAAAACAAT GTTTCTACCTTT CTTAGGTTAAGAAACAAT GTTTCTTA 1766 CCTTTAGTAAAAACAAAAATCATGGAGCCAGTGTTTCTTTCTT GT GTTT GAAGATACTCTTTA 1829 ATGTATACACCTTT GTGCTTCTTCTAAGAACTGCT GTTGTTTTCCCTGCTACAGACAACAATA 1892 CAGTAAAAGAGGCAGAGAATATAGACCT GAAGATTAT GTTTCCCACCATTAAAGCCAGT GGAG 1955 TGCTCTTAACCACAGAACTATACTTAGCATTCCCTTTTTTCATTCTTAATTTTAGCAACAGGTC 2018 TACATTTAAGCTTTAATTGAAATTAAT GCCTATAAATT GAAATAGATTAATTTTCATAACTGA 2081 AAATTCT CTGAAAAT GCCAATATACTTT GTAAGTGGCTCCAATAAGCATAGTATGGGATTGTT 2144 CTTGGGATGGT GGAAGACATTACAGTATT CAGATATTTT GT GT CAGCACTGATATTTGACACT 2207 GCAAACACAATATTT CAGACCTGCT CAAGGT CCATCTGCACTT CAGCCACCTGTTCT GT GAAG 2270 AGAAAAAAAAAAAAA

Figure 4 Nucleotide and deduced amino acid sequence of chicken sulfotransferase cDNA. The nucleotides are numbered from the $5^{\prime}$ end (transcriptional start site, as determined by $5{ }^{\prime}$ RACE analysis, is +1 ). Amino acids are numbered in italics. The open reading frame consists of 959 nucleotides and encodes 312 amino acids. 


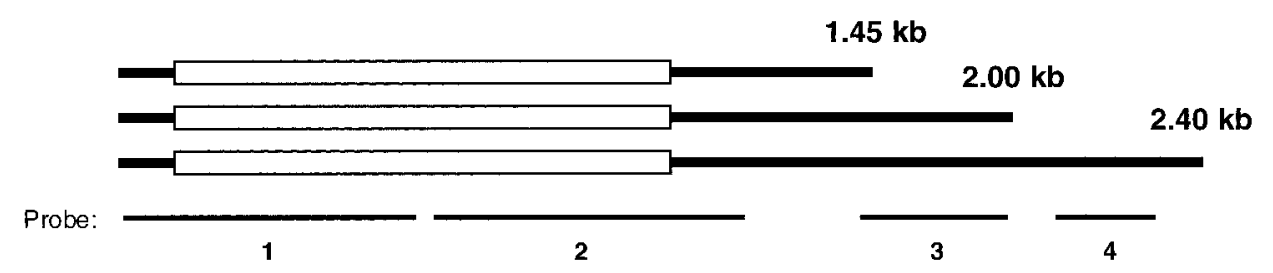

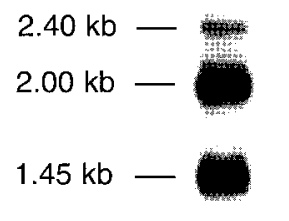

1

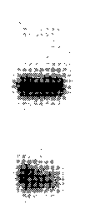

2

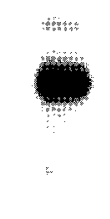

3
4

Figure 5 Northern blot analysis of liver chicken sulfotransferase transcripts using probes corresponding to different regions of the cDNA. Poly $(\mathrm{A})$ mRNA was used for the analysis. Probes were prepared by restriction enzyme digestion of the cDNA. Probe 1 corresponds to nt $1-635$; probe 2 is nt $636-1183$; probe 3 is nt 1396; probe 4 is nt 2025-2235.

respectively (Fig. 7). This activity is sensitive to inhibition by low levels of N-ethylmaleimide (50\% inhibition at $0.1 \mathrm{mM})$. Aryl and estrogen, but not hydroxysteroid, sulfotransferases are sensitive to low levels of thiol reagents (Glasier et al. 1992). These results demonstrate that the isolated chicken sulfotransferase cDNA encodes a protein with sulfotransferase activity; however, it should be emphasized that the true endogenous substrate is not known.

\section{Discussion}

By using the mRNA differential display technique, we have identified and cloned a GH-regulated cDNA that encodes a protein with sulfotransferase activity. This gene is expressed in liver and muscle and is found at higher levels in livers of 5-week-old normal chickens, compared with GHR-deficient dwarf chickens of the same age and genetic background. At 5 weeks of age, endogenous GH levels are near maximum in normally growing birds (Burnside \& Cogburn 1992), thus any difference in levels of expression is likely to be a consequence of GH action. GHR-deficient dwarf chickens do have other endocrine abnormalities resulting from the absence of $\mathrm{GH}$ action (Tixier-Boichard et al. 1989). For example, dwarf chickens are slightly hypothyroid (Stewart et al. 1984), and differences in gene expression could be a consequence of thyroid deficiency, or changes in any hormone whose activity is controlled by GH. However, we have demonstrated that at the level of steady-state mRNA, this sulfotransferase is rapidly, albeit modestly increased by in vivo $\mathrm{GH}$ administration. The time course of response to GH was biphasic, with increases detected by $1 \mathrm{~h}$, and a peak at $4 \mathrm{~h}$, followed by a decline for the next $12 \mathrm{~h}$. Levels were increased again, at $24 \mathrm{~h}$ post-injection. A biphasic response of insulin-like growth factor-I (IGF-I) to GH has also been reported (Johnson et al. 1989). While these results indicate that the expression of chicken sulfotransferase is regulated by $\mathrm{GH}$, these experiments do not discriminate between direct and indirect actions. It is conceivable that the biphasic response is the result of initial direct action by $\mathrm{GH}$ on gene transcription, followed by a delayed indirect mechanism that alters stability of the mRNA. Confirmation of these actions will require nuclear run-on assays and promoter analysis. The three hepatic chicken sulfotransferase transcripts originate from a single gene and differ in their $3^{\prime}$ UTR. Other genes in the sulfotransferase gene family use alternative polyadenylation sites or alternative $5^{\prime}$ start sites to generate multiple transcripts (Kong et al. 1992, Bernier et al. 1994). The alternative noncoding sequences might have important functions in regulation of gene activity by affecting mRNA stability or translational activity. The $2.5 \mathrm{~kb}$ transcript in liver is present at very low levels on most Northern blots. This could reflect an intrinsic instability 


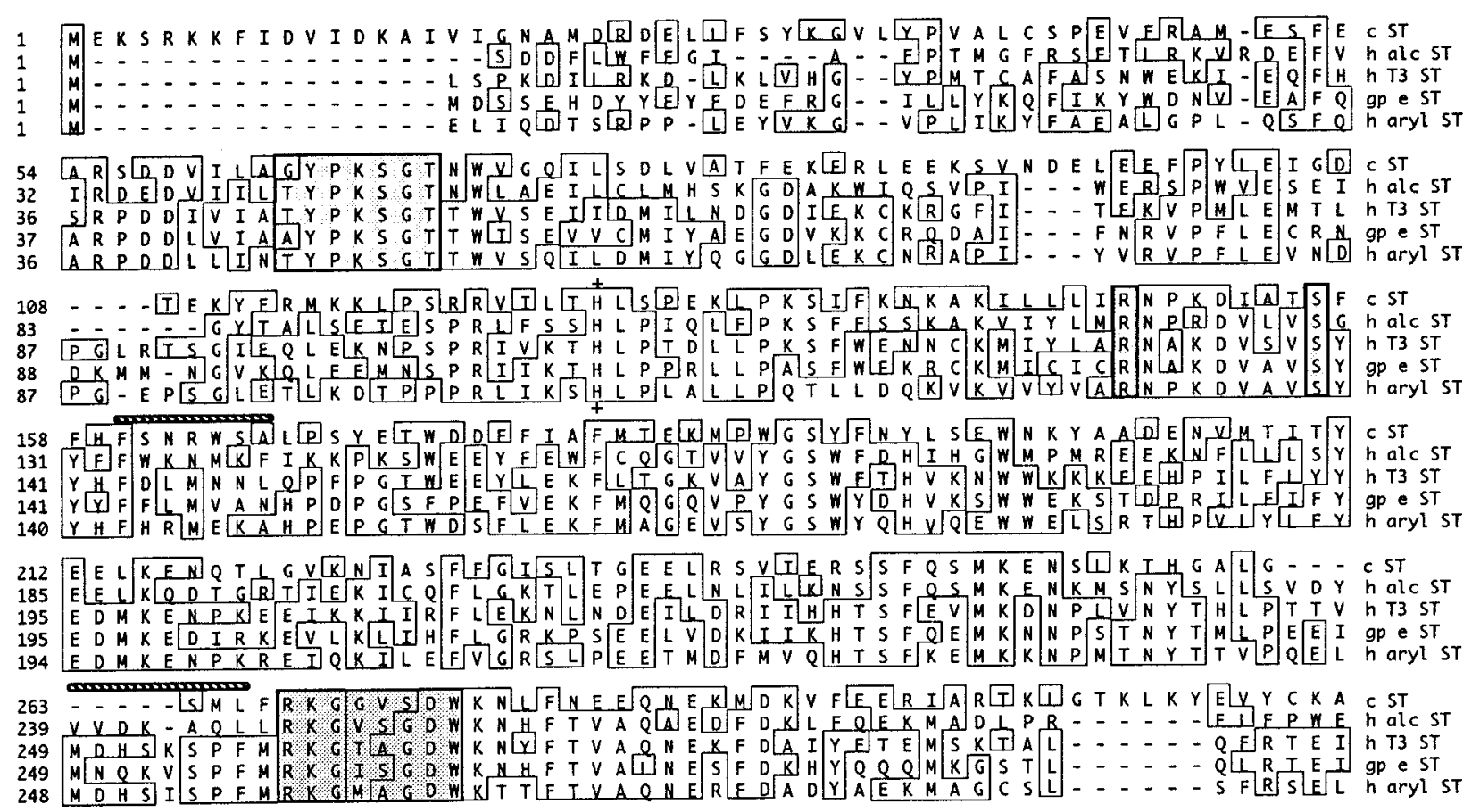

Figure 6 Comparison of the predicted amino acid sequence of chicken sulfotransferase with human alcohol sulfotransferase (h alc ST, \#JC1223 (Kong et al. 1992)), human aryl sulfotransferase (h aryl ST, \#A55451 (Bernier et al. 1994)), thyroid hormone sulfotransferase (h T3 ST, \#U95726) and guinea pig estrogen sulfotransferase (gp e ST, \#A44011 (Tomizuka et al. 1994)). Alignment was performed using the Clustal method of the DNAStar MegAlign program. Shaded boxes indicate residues involved in binding PAPS. The conserved histidine thought to be involved in catalysis is indicated by ' + '. Hatched lines indicate analogous regions that form the steroid-binding pocket of estrogen sulfotransferase (Kakuta et al. 1998).

due to sequences in the $3^{\prime}$ UTR. It appears that there is tissue-specific processing of the sulfotransferase gene or mRNA in the chicken, since in muscle only the 2.4 and a $4.0 \mathrm{~kb}$ transcript are expressed. We are in the process of cloning the muscle cDNA in order to determine the structure of these hybridizing species. Preliminary results suggest the larger transcript in muscle contains two retained introns.

Chicken sulfotransferase shows only $28-32 \%$ sequence similarity with mammalian sulfotransferases, but has a higher level of similarity in the domains (particularly the PAPS-binding domains) which are conserved in other sulfotransferases. Sulfotransferases are involved in the metabolism of a wide variety of endogenous materials (hormones, neurotransmitters and bile acids) and exogenous chemicals (drugs, pesticides and carcinogens) (Mulder \& Jakoby 1990). These enzymes catalyze a sulfoconjugation reaction which increases the water solubility of the substrate, thereby facilitating excretion (Mulder \& Jakoby 1990). Sulfotransferases can also play a regulatory role by transforming compounds such as steroid hormones into receptor-inactive forms (Demyan et al. 1992). In this role, sulfotransferases can effectively regulate the target cell sensitivity to hormonal steroids and thus the downstream expression of hormone-responsive genes within target tissues. Computer analysis does not allow assignment of chicken sulfotransferase to any known family of sulfotransferases, and its endogenous substrate is not yet known. There have been several reports of GH stimulation of estrogen and thyroid hormone sulfotransferase activity, where regulation appears to be related to the sex difference in GH secretion (Yamazoe et al. 1987, Gong et al. 1992). We have not noted any differences in the levels of chicken sulfotransferase mRNA between liver (or muscle) of male and female chickens (unpublished results), and chicken sulfotransferase may represent a different class of sulfotransferase. However, even though we do not know the physiological substrate of this sulfotransferase, it can use the steroid hormones estradiol and corticosterone as substrates. Glucocorticoids and estrogens have long been known for their antagonism of GH action (Freundenberger \& Hashimoto 1937, King et al. 1996). For example, in the liver, estrogens can inhibit IGF-I synthesis, and as a consequence, reduce growth (Murphy \& Friesen 1988). We speculate that $\mathrm{GH}$ induction of sulfotransferase activity may play a positive role in protecting target tissues from the growthinhibitory action of steroid hormones during the rapid growth periods of animals. With restricted tissue expression of this sulfotransferase, $\mathrm{GH}$ would not reduce 


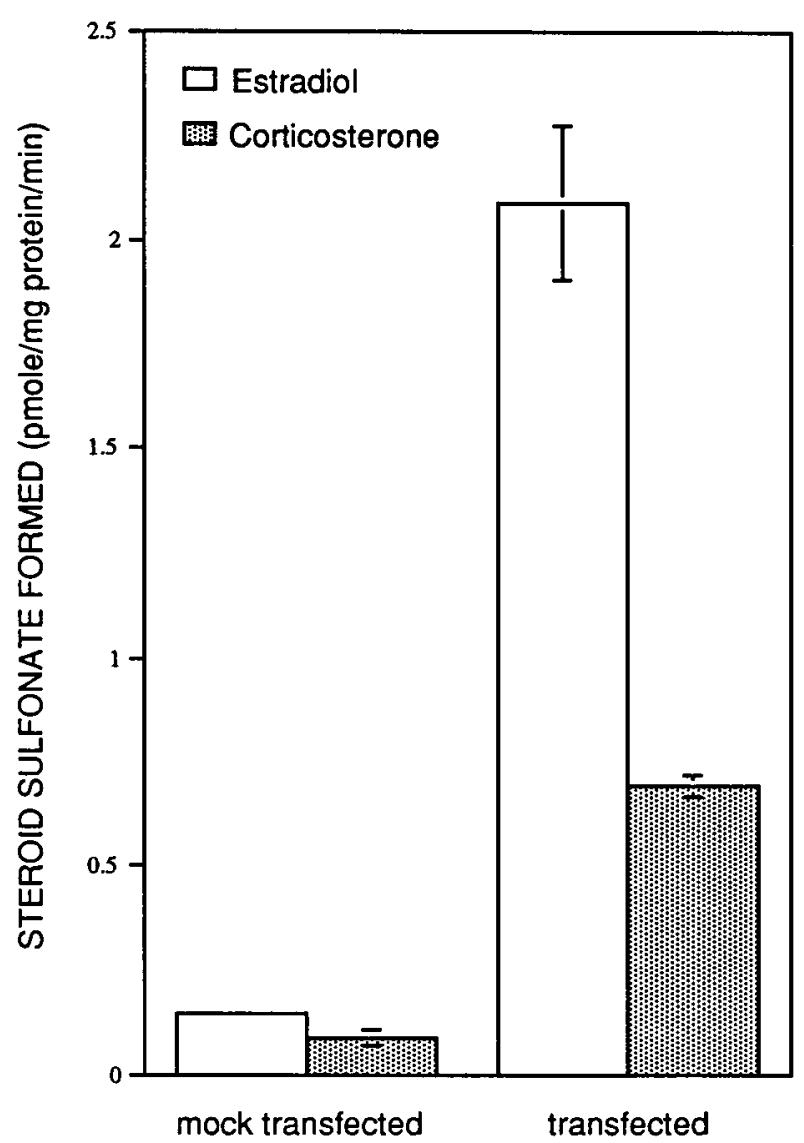

Figure 7 Sulfotransferase activity expressed by 293 cells transfected with chicken sulfotransferase cDNA. Cytosolic extracts of mock-transfected and transfected 293 cells were prepared and assayed for sulfotransferase activity as described in Materials and Methods, using either $\left[{ }^{3} \mathrm{H}\right]$ estradiol or $\left[{ }^{3} \mathrm{H}\right]$ corticosterone as substrate. Error bars are S.E.M. of triplicate determinations. (The error bar of mock-transfected cells using $\left[{ }^{3} \mathrm{H}\right]$ estradiol is too small to be seen.)

the positive effects of steroids on growth of bone or reproductive organs.

In order to fully unravel the complexity of GH action, there is a need for identification of more genes, and systems for analysis of GH-dependent gene expression. Information on genes whose expression is regulated by $\mathrm{GH}$ will further our understanding of $\mathrm{GH}$ action. In addition, analysis of the promoters of these genes can be used to establish systems for studying GH signal transduction mechanisms. To date, only five GH-regulated genes have been isolated and the promoter elements involved in GH regulation identified (c-fos, Spi $2 \cdot 1$, insulin, cytochrome P450 3A10 hydroxylase and acid labile subunit) (Yoon et al. 1990, Le Cam et al. 1994, Meyer et al. 1994, Sliva et al. 1994, Subramanian et al. 1995, Galsgaard et al. 1996, Ooi et al. 1998). The expression of these genes differs in terms of temporal regulation and tissue-specific expression, in response to $\mathrm{GH}$. The lack of information on other GH-regulated genes has limited our understanding of the diverse nature of the molecular mechanisms involved in $\mathrm{GH}$ action and characterization of other GH-regulated genes and the cis- and trans-active elements involved in their GH-dependent gene expression is needed. We have isolated a genomic clone of chicken sulfotransferase and sequenced a portion of the promoter. A comparison of the promoter sequence with the palindromic motif which interacts with signal transducers and activators of transcription (Le Cam et al. 1994, Galsgaard et al. 1996, Ihle 1996) indicates the presence of several potential GH regulatory elements (GHRE). Future experiments are aimed at determining if the promoter of chicken sulfotransferase is $\mathrm{GH}$ responsive, and functional localization of the GHRE(s).

\section{Acknowledgements}

We thank Dr Charles Strott of the NIH for helpful discussions about the sequence of chicken sulfotransferase. H C and S K A contributed equally to this work. This work was supported by USDA grants 91-37206-6689 and 95-37206-2240.

\section{References}

Agarwal SK, Cogburn LA \& Burnside J 1995 Comparison of gene expression in normal and growth hormone receptor deficient dwarf chickens reveals a novel growth hormone regulated gene. Biochemical and Biophysical Research Communications 206 153-160.

Altschul SF, Gish W, Miller W, Myers EW \& Lipman J 1990 Basic Local Alignment Search Tool. Journal of Molecular Biology 215 403-410.

Bernier F, Leblanc G, Labrie F \& Luu-The V 1994 Structure of human estrogen and aryl sulfotransferase gene-two mRNA species issued from a single gene. Journal of Biological Chemistry 269 28200-28205.

Berry SA, Manthei RD \& Seelig S 1986 Ontogenesis of growth hormone $(\mathrm{GH})$-responsive hepatic gene products: lack of correlation with hepatic GH receptor content. Endocrinology 119 2290-2296.

Burnside J \& Cogburn LA 1992 Developmental expression of hepatic growth hormone receptor and insulin-like growth factor-I mRNA in the chicken. Molecular and Cellular Endocrinology 89 91-96.

Burnside J, Liou SS \& Cogburn LA 1991 Molecular cloning of the chicken growth hormone receptor complementary DNA: Mutation of the gene in sex-linked dwarf chickens. Endocrinology 128 3183-3192.

Chirgwin JM, Przybla AE, MacDonald RJ \& Rutter WJ 1979 Isolation of biologically active ribonucleic acid from sources enriched in ribonuclease. Biochemistry 18 5294-5299.

Demyan WF, Song CS, Kim DS, Her S, Gallwitz W, Rao TR, Slomczynska M, Chatterjee B \& Roy AK 1992 Estrogen sulfotransferase of the rat liver: Complementary DNA cloning and age- and sex-specific regulation of messenger RNA. Molecular Endocrinology 6 589-597.

Dugaiczk A, Haron JA, Stone EM, Dennison OE, Rothblum KN \& Schwartz RJ 1983 Cloning and sequencing of a deoxyribonucleic acid copy of glyceraldehyde-3-phosphate dehydrogenase messenger ribonucleic acid isolated from chicken muscle. Biochemistry 22 $1605-1613$. 
Freundenberger CB \& Hashimoto EI 1937 A summary of data for the effects of ovariectomy on body growth and organ weights of young albino rats. American Journal of Anatomy 62 93-119.

Galsgaard ED, Gouilleux F, Groner B, Serup P, Nielsen JH \& Billestrup N 1996 Identification of a growth hormone-responsive STAT5-binding element in the rat insulin 1 gene. Molecular Endocrinology 10 652-660.

Gish W \& States DJ 1993 Identification of protein coding regions by database similarity search. Nature Genetics 3 266-272.

Glasier MA, Glutek SM \& Hobkirk R 1992 Comparison of estrogen sulfotransferase and pregnenolone sulfotransferase of guinea pig. Steroids $\mathbf{5 7}$ 295-300.

Gong DW, Murayama N, Yamazoe Y \& Kato R 1992 Hepatic triiodothyronine sulfation and its regulation by growth hormone and triiodothyronine in rats. Journal of Biochemistry 112 112-116.

Huang N, Cogburn LA, Agarwal SK, Marks HL \& Burnside J 1993 Over-expression of a truncated growth hormone receptor in the sex-linked dwarf chicken: Evidence for a splice mutation. Molecular Endocrinology 7 1391-1398.

Ihle J 1996 STATs: Signal transducers and activators of transcription. Cell 84 331-334.

Johnson TR, Blossey BK, Denko CW \& Ilan J 1989 Expression of insulin-like growth factor I in cultured rat hepatocytes: Effects of insulin and growth hormone. Molecular Endocrinology 3 580-587.

Kakuta Y, Pedersen LG, Carter CW, Negishi M \& Pedersen LC 1998 Crystal structure of estrogen sulphotransferase. Nature Structural Biology 4 904-908.

King APJ \& Carter-Su C 1995 Dexamethasone-induced antagonism of GH action by down regulation of GH binding in 3T3-F442A fibroblasts. Endocrinology 136 4796-4803.

King APJ, Tseng M, Logsdon CD, Billestrup N \& Carter-Su C 1996 Distinct cytoplasmic domains of the growth hormone receptor are required for glucocorticoid- and phorbol ester-induced decreases in growth hormone $(\mathrm{GH})$ binding. Journal of Biological Chemistry 271 18088-18094.

Kong AT, Yang L, Ma M, Tao D \& Bjornsson TD 1992 Molecular cloning of the alcohol/hydroxysteroid form (hSTa) of sulfotransferase from human liver. Biochemical and Biophysical Research Communications 187 448-454.

Kozak M 1989 The scanning model for translation: An update. Journal of Cell Biology 108 229-235.

Le Cam A, Pantescu V, Paquereau L, Legraverend C, Fauconnier G \& Asins G 1994 cis-Acting elements controlling transcription from rat serine protease inhibitor $2 \cdot 1$ gene promoter. Journal of Biological Chemistry $26921532-21539$.

Liang P \& Pardee AB 1992 Differential display of eukaryotic messenger RNA by means of the polymerase chain reaction. Science 257 967-971.

Liang P, Averboukh L, Keyomarsi K, Sager R \& Pardee AB 1992 Differential display and cloning of messenger RNAs from human breast cancer versus mammary epithelial cells. Cancer Research $\mathbf{5 2}$ 6966-6968.

Liang P, Averboukh L \& Pardee AB 1993 Distribution and cloning of eukaryotic mRNAs by means of differential display: refinements and optimization. Nucleic Acids Research 21 3269-3275.

Luo L \& Murphy LJ 1989 Dexamethasone inhibits growth hormone induction of insulin-like growth factor-I (IGF-I) messenger ribonucleic acid (mRNA) in hypophesectomized rats and reduced IGF-I mRNA in the intact rat. Endocrinology 125 165-171.

Marks HL 1982 Selection for body weight at eight weeks of age in dwarf and normal meat-type chickens originating from a common control population background. Poultry Science 62 227-234.
Meyer DJ, Campbell GS, Cochran BH, Argetsinger LS, Larner AC, Finbloom DS, Carter-Su C \& Schwartz J 1994 Growth hormone induces a DNA binding factor related to the interferon-stimulated 91-kDa transcription factor. Journal of Biological Chemistry 269 4701-4704.

Mulder GJ \& Jakoby WB 1990 Sulfation. In Conjugation Reactions in Drug Metabolism, pp 107-162. Ed. GJ Mulder. London: Taylor and Francis.

Murphy LJ \& Friesen HG 1988 Differential effects of estrogen and growth hormone on uterine and hepatic insulin-like growth factor I gene expression in the ovariectomized hypophysectomized rat Endocrinology 122 325-332.

Ooi GT, Hurst KR, Poy MN, Rechler MM \& Boisclair YR 1998 Binding of STAT5a and STAT5b to a single element resembling a $\gamma$-interferon activated sequence mediates the growth hormone induction of the mouse acid-labile subunit promoter in liver cells. Molecular Endocrinology 12 675-687.

Radecki SV, McCann-Levorse L, Agarwal SK, Burnside J, Proudman JA \& Scanes CG 1997 Chronic administration of growth hormone $(\mathrm{GH})$ to adult chickens exerts market effects on circulating concentrations of insulin-like growth factor-I (IGF-I), IGF binding proteins, hepatic $\mathrm{GH}$ regulated gene I and hepatic $\mathrm{GH}$ receptor mRNA. Endocrine 6 117-124.

Sambrook J, Fritsch EF \& Maniatis T 1989 Molecular Cloning: A Laboratory Manual, pp 1·1-18-88. Cold Spring Harbor, New York: Cold Spring Harbor Laboratory Press.

Sliva D, Wood TJJ, Schindler C, Lobie PE \& Norstedt G 1994 Growth hormone specifically regulates serine protease inhibitor gene transcription via gamma-activated sequence-like DNA elements. Journal of Biological Chemistry $26926208-26214$.

Stewart PA, Washburn KW \& Marks HL 1984 Effect of the $d w$ gene on growth, plasma hormone concentrations and hepatic enzyme activity in a randombred population of chickens. Growth 48 59-73.

Subramanian A, Teixeira J, Wang J \& Gil G 1995 A STAT factor mediates the sexually dimorphic regulation of hepatic cytochrome P450 3A10/lithocholic acid 6 beta-hydroxylase gene expression by growth hormone. Molecular and Cellular Biology 15 4672-4682.

Tixier-Boichard M, Huybrechts LM, Kuhn E, Decuypere E, Charrier J \& Mongin P 1989 Physiological studies on the sex-linked dwarfism of the fowl: A review on the search for the gene's primary effect. Genetique Selection Evolution 21 217-234.

Tomizuka T, Oeda T, Tamura Y, Yoshida S \& Strott CA 1994 Characterization of guinea pig estrogen sulfotransferase expressed by Chinese hamster ovary cell-K1 stable transfectants. Endocrinology 135 938-943.

Yamazoe Y, Manabe S, Murayama N \& Kato R 1987 Regulation of hepatic sulfotransferase catalyzing the activation of $\mathrm{N}$ hydroxyarylamide and N-hydroxyarylamine by growth hormone. Molecular Pharmacology 32 536-541.

Yamazoe Y, Nagata K, Ozawa S \& Kato R 1994 Structural similarity and diversity of sulfotransferases. Chemico-Biological Interactions $\mathbf{9 2}$ $107-117$.

Yoon JB, Towle JC \& Seelig S 1987 Growth hormone induces two mRNA species of the serine protease inhibitor gene family in rat liver. Journal of Biological Chemistry 262 4284-4289.

Yoon JB, Berry SA, Seelig S \& Towle HC 1990 An inducible nuclear factor binds to a growth hormone-regulated gene. Journal of Biological Chemistry 265 19947-19954.

Received 2 June 1998

Accepted 20 October 1998 